\title{
Field Study on Adaptive Thermal Comfort in Naturally Ventilated Secondary School Buildings in Nepal
}

\author{
Mishan Shrestha ${ }^{1, *}$, Hom Bahadur Rijal ${ }^{1}$, Masanori Shukuya ${ }^{1}$ \\ ${ }^{1}$ Graduate School of Environmental and Information Studies, Tokyo City University, Yokohama, Japan \\ Corresponding Email: born2winmission123@gmail.com
}

\begin{abstract}
:
Most of the classroom in Nepalese school buildings are thermally less acceptable due to the poor thermal insulation. They are extreme cold in winter and extreme hot in summer season leading for the discomfort in classroom. Thermally uncomfortable classroom causes the negative impact in the academic performance of students. Therefore, there should be serious attention to improve the indoor thermal environment of classroom. There are limited indoor thermal environment studies conducted in Nepalese residential buildings but not at all in school buildings yet.

This study investigated the students' perceptions on thermal comfort inside the classroom of secondary school buildings during the autumn season of 2017 in a temperate climate (Dhading, Kathmandu and Nuwakot districts) of Nepal. 22 classrooms (33 students in average in each class) of 8 school buildings with a total of 818 students aged $12-18$ years, 329 (40\%) males and 489 (60\%) females were participated in the survey. The two simultaneous surveys: questionnaire survey and thermal measurement survey were conducted during the regular lesson periods in each classroom. Students voted at the beginning, in the middle and at the end of the class in minutes' lecture.

About $76 \%$ responses were found to be in either of slightly cold, neutral or slightly hot. The results show that the comfort temperature of students was around $28{ }^{\circ} \mathrm{C}, 26^{\circ} \mathrm{C}$ and $24^{\circ} \mathrm{C}$ in Dhading, Kathmandu and Nuwakot districts, respectively. However, the mean comfort temperature and preferred temperature was found to be around $27^{\circ} \mathrm{C}$ and $26^{\circ} \mathrm{C}$ respectively. The findings of this study may hopefully invoke the awareness of the school building designers, teachers and students to maintain the thermally comfortable school buildings without using mechanical system.
\end{abstract}

Keywords: Naturally Ventilated School Building, Thermal Comfort, Thermal Sensation, Comfort Temperature, Preferred Temperature

\section{Introduction}

The students spend approximately $30 \%$ of their lives in school [1] for their study and other educational activities. The activities of the students are dependent on indoor thermal environment of classroom. Thermal comfort is related to the performance of students. Thermal comfort is the state of mind that expresses the satisfaction with the thermal environment [2]. Extremely high or low indoor air temperature of classroom interrupts the learning ability of students and difficult to focus on their study. Thermally uncomfortable indoor environment causes the health problems and less productivity of learning for no apparent reason [2]. In Nepal, most of the classrooms may not be able to meet the recommended thermal comfort condition. A satisfactory classroom is where more than $80 \%$ of the students perceive it thermally acceptable [2]. The acceptance of indoor thermal environment is directly connected with the building's performance [3]. Due to the lack of good insulation, ventilation, absence of windows has the negative impact to the indoor thermal comfort of students. Most of the Nepalese school buildings are naturally ventilated and poor insulation and ventilation system. The temperatures including other physical parameters like humidity, air velocity, carbon dioxide are often easily varied in that type of buildings. In residential and office buildings, people use adaptive behavior to adjust thermal comfort. But it is not easy for the students inside the classroom as they are restricted to change their clothes, position, window open-close activities [4].

Most of the countries have been conducting the thermal comfort survey in school buildings (Table 1). But, in case of Nepal, such kind of study has not been conducted at all except in few residential buildings [5]. International standards $[2,6,7]$ are made for the indoor thermal comfort predictions of residential and office buildings. The frequently used standards are: ASHRAE-55 [2], ISO7730 [7] and CEN 15251 [6]. ASHRAE-55 describes a method of compliance for designed spaces and adaptive method Fangers' Predicted Mean Vote (PMV) that presents the for naturally ventilated spaces. ISO7730 is based on method 
Field Study on Adaptive Thermal Comfort in Naturally Ventilated Secondary School Buildings in Nepal

Table 1: Summary of previous thermal comfort studies

\begin{tabular}{|c|c|c|c|c|c|c|}
\hline Location & Climate & Time of survey & References & Adaptive thermal comfort model & $\mathbf{T}_{\mathbf{c}}\left[{ }^{\circ} \mathbf{C}\right]$ & $\mathbf{T}_{\mathbf{n}}\left[{ }^{\circ} \mathbf{C}\right]$ \\
\hline China & Sub-tropical & March-April 2005 & Zhang et al., 2007 [16] & $\mathrm{TSV}=0.0448 \mathrm{~T}_{o p}-0.9628, \mathrm{R}^{2}=0.3743$ & $21.5-24.8$ & 21.5 \\
\hline Taiwan & Sub-tropical & Sept 2005-Jan 2006 & Hwang et al., 2009 [13] & $\mathrm{MSV}=0.01 \mathrm{~T}_{o p}-0.30, \mathrm{R}^{2}=0.3743$ & $17.6-30$ & $22.7-29.1$ \\
\hline China & Sub-tropical & Mar 2005-May 2006 & Yao et al., 2010 [17] & $\mathrm{T}_{c}=0.6 \mathrm{~T}_{\text {out }}+9.85, \mathrm{R}^{2}=0.9736$ & $16-30$ & 22.8 \\
\hline Taiwan & Sub-tropical & Sept 2005-Feb 2006 & Liang et al., 2012 [18] & $\mathrm{T}_{n}=0.62 \mathrm{~T}_{o m}-12.1, \mathrm{R}^{2}=0.923$ & 22.4-29.2 & $22.7-29.1$ \\
\hline Iran & Hot and Dry & 2012-2013 & Hadded et al., 2016 [11] & $\mathrm{TSV}_{m}=0.268 \mathrm{~T}_{o p}-6.251, \mathrm{R}^{2}=0.822$ & $22-25$ & 23.3 \\
\hline Australia & Sub-tropical & Summer 2013 & de Dear et al., 2015 [14] & $\mathrm{TSV}_{m}=0.12 \mathrm{~T}_{o p}+2.78, \mathrm{R}^{2}=0.76$ & $19.5-26.6$ & 22.4 \\
\hline China & Sub-tropical & Oct 2013-Apr 2014 & Wang et al., 2016 [19] & $\mathrm{TSV}_{\mathrm{m}}=0.155 \operatorname{Tin}-2.9681$ & $16-22.4$ & 18 \\
\hline China & Sub-tropical & Nov and Dec 2014 & Liu et al., 2016 [20] & $\mathrm{TSV}_{\mathrm{m}}=0.1801 \mathrm{Top}-2.7174$ & $15-20$ & 18 \\
\hline Hong Kong & Sub-tropical & Aug-Oct, 2015 & Fang et al., 2018 [21] & $\mathrm{MTSV}=0.198 \mathrm{~T}_{o p}-4.789, \mathrm{R}^{2}=0.774$ & $21.6-26.8$ & 24.1 \\
\hline India & Composite & Apr-June, 2015 & Singh et al., $2018[23]$ & $\mathrm{T}_{\text {comf }}=0.49 \mathrm{~T}_{r m}+13.8, \mathrm{R}^{2}=0.59$ & $23-32$ & 29.8 \\
\hline India & Composite & Peak summer & Kumar et al., 2018 [22] & $\mathrm{TSV}=0.19 \mathrm{~T}_{\mathrm{a}}+5.04, \mathrm{R}^{2}=0.37$ & $21.2-31.8$ & 26.5 \\
\hline India & Composite & Aug 2015-Feb 2016 & Aradhana, 2018 [24] & $\mathrm{TSV}=0.056 \mathrm{~T}_{o p}-1.53, \mathrm{R}^{2}=0.22$ & $15.3-33.7$ & 27.1 \\
\hline
\end{tabular}

TSV: Thermal sensation vote, MSV: Mean sensation vote, TSV $/$ MTSV: Mean thermal sensation vote,

$T_{c} / T_{\text {comf }}$ : Comfort temperature, $T_{n}:$ Neutral temperature, $T_{o p}$ : Operative temperature, $T_{\text {out }}$ : Outdoor air temperature,

$T_{\text {om }}$ : Mean monthly outdoor temperature, $T_{i n}$ : Indoor air temperature, $\mathrm{T}_{\mathrm{a}}$ : Air temperature

of calculation of mean thermal sensation of people and the Predicted Percentage of people Dissatisfied (PPD) with the thermal environments. CEN 15251 specifies indoor environmental parameters for design and performance of buildings addressing air quality, thermal environment, lighting and acoustics. The particular thermal comfort standard for the school buildings has not been developed. This paper, therefore, investigates, students' comfort level in naturally ventilated school buildings of Nepal.

Several studies clarified the importance of adaptive thermal comfort in school buildings. Table 1 presents the summary of thermal comfort studies conducted in different areas to evaluated the comfort status of students in school buildings. These studies established their own comfort models and comfort temperature. A long-term thermal comfort field study conducted in air- conditioned and non-air-conditioned school buildings over 3,544 students in Hawaii by Kwok [8] found $75 \%$ of the classrooms did not able to meet the comfort requirements prescribed by ASHRAE-55 [2]. This study estimated that the preferred temperature of the students is higher than the neutral temperature in naturally ventilated school buildings than in air-conditioned. The neutrality of the students is different than adults due to the activity in classroom, clothing and environmental parameters. This was found in the study of Teli et al. [9-10] which concluded that the comfort temperature of students is $2 \mathrm{~K}$ lower than adults. The similar kind of result is found in the study conducted in NV classrooms in Iran by Haddad et al. [11]. The comfort temperature found in this study was lower than the temperature prescribed in ASHRAE adaptive model [2] during warm season. Studies conducted in Taiwan $[12,13]$ for summer months found that the thermal sensitivity of the students is more in summer than winter. Further, Liang et al. [18] investigated the effects of buildings envelope energy regulations on thermal comfort level in NV classrooms in primary and secondary schools. They found the significant impact of building energy regulation on the level of thermal comfort. de Dear et al. [14] conducted a study in Australian primary classrooms. This study found the same value of comfort and preferred temperature of $22.5{ }^{\circ} \mathrm{C}$ which is lower than adults under the same thermal environments. A study conducted over 10 million US secondary school students over 13 years found the negative impact to exam result in hot weather [15]. They found $0.55^{\circ} \mathrm{C}$ increase in average temperature over the year, there was a $1 \%$ falling in learning.

Our study aims to find the thermal comfort level of the students under the naturally ventilated condition. The main objectives of this study are:

- To find the thermal perception of the students under the naturally ventilated mode.

- To find the comfort temperature and preferred temperature of the students.

- To compare data of this study with thermal comfort standards 


\section{Methodology}

\subsection{Study areas and buildings}

A field study was conducted in three districts (Dhading, Kathmandu and Nuwakot) in temperate climate of Nepal in September-October of 2017. The survey was conducted in 22 classrooms of 8 naturally ventilated school buildings. Most of the buildings were two stories. The buildings were constructed using brick and stone wall, mortar plaster. The structure of the building was Reinforced Concrete Construction (RCC). The general type of buildings and classrooms are shown in Figure 1. Buildings were not well insulated and the students have to accept the variety of indoor thermal conditions. The students were participated from grade 8,9 and 10 from each school. Altogether 818 students were participated in the field study: 489 females (60\%), 329 males (40\%) with age group of 12-18 years. Each student voted three times in 45 minutes' lecture and we obtained 2454 responses. The average number of students in each classroom were 33. The survey was conducted in between 10:00 - 16:00.

\subsection{Thermal measurements}

The physical parameters such as air temperature, relative humidity, globe temperature, surface temperature, air movement and lighting level were measured using digital instruments. Table 2 presents the details of digital instruments used in the field study to measure the environmental conditions. The parameters were recorded at a height of around $1 \mathrm{~m}$ above the floor level. The instruments were placed at the center of classroom for data measurement. The parameters were measured three times in the interval of 15 minutes in 45 minutes of lecture.
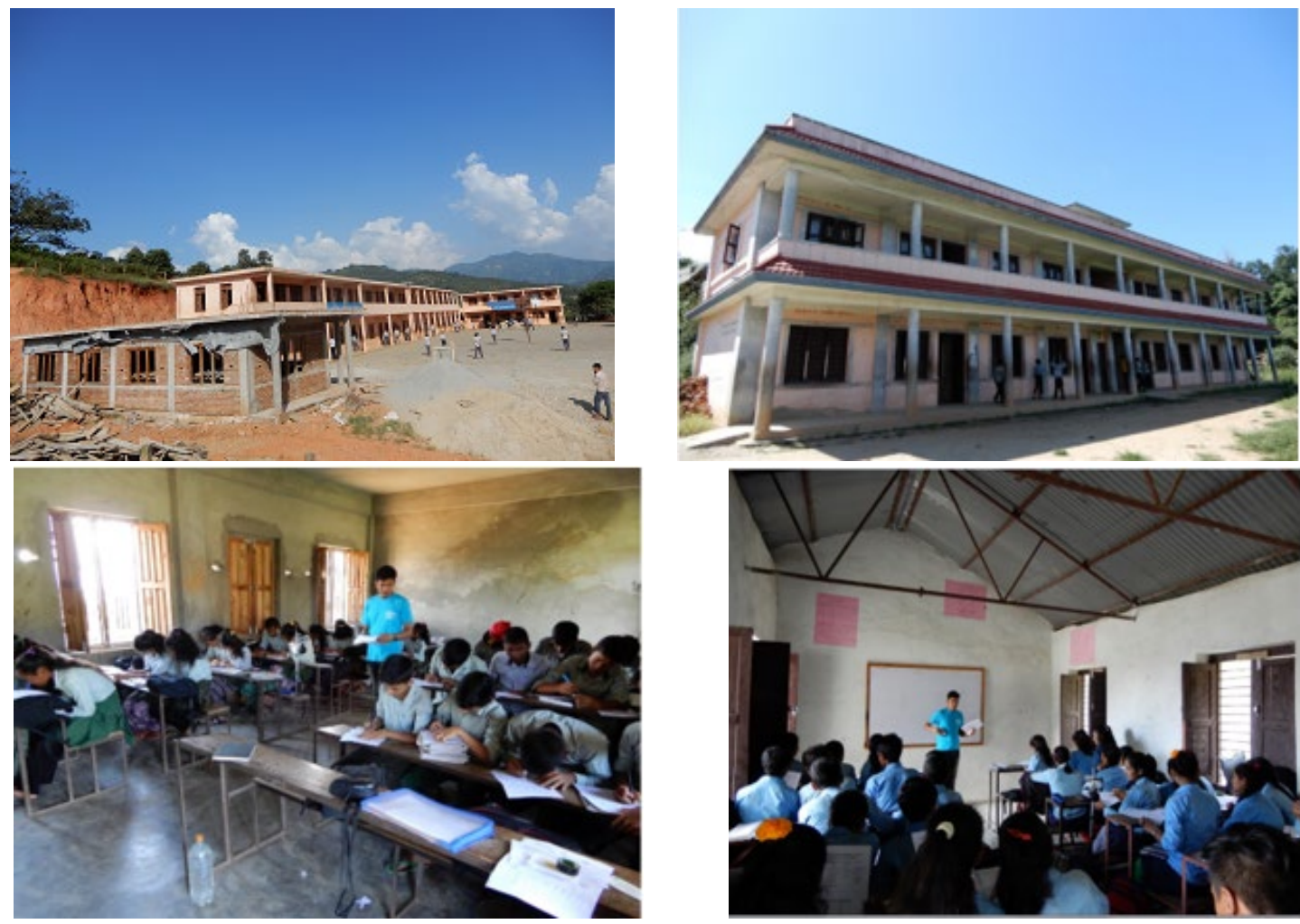

Figure 1: View of surveyed buildings and classrooms

Table 2: Description of survey instruments

\begin{tabular}{lllll}
\hline Parameter measured & Sensors & Range & Accuracy & Name of instruments \\
\hline Air temperature & Thermistor & $0-55^{\circ} \mathrm{C}$ & $\pm 0.5^{\circ} \mathrm{C}$ & TR-74Ui \\
Relative humidity & Polymer membrane & $10-95 \%$ & $\pm 5 \% \mathrm{RH}$ & $\mathrm{TR}-74 \mathrm{Ui}$ \\
Globe temperature & Metallic globe, $75 \mathrm{~mm}$-diameter globes & -60 to $155^{\circ} \mathrm{C}$ & $\pm 0.3^{\circ} \mathrm{C}$ & $\mathrm{Tr}-52 \mathrm{i}, \mathrm{SIBATA}, 080340-75$ \\
Air velocity & Hot-wire anemometer & 0 to $30 \mathrm{~m} / \mathrm{s}$ & $\pm 0.015 \mathrm{~m} / \mathrm{s}$ & $\mathrm{TSI} 9535$ \\
Carbon dioxide & Nondispersive infrared analyzer & 0 to $9,999 \mathrm{ppm} \pm 50 \mathrm{ppm}$ & TR-76Ui \\
\hline
\end{tabular}


Table 3: Description of sensation scales

\begin{tabular}{llll}
\hline Thermal sensation & Thermal Preference & Overall comfort & Thermal acceptance \\
\hline 1. Very cold & 1. Much warmer & 1. Very comfortable & 0. Acceptable \\
2. Cold & 2. A bit Warmer & 2. Moderately Comfortable & 1. Unacceptable \\
3. Slightly cold & 3. No change & 3. Slightly comfortable & \\
4. Neutral & 4. A bit cooler & 4. Slightly uncomfortable & \\
5. Slightly hot & 5. Much cooler & 5. Moderately uncomfortable & \\
6. Hot & & 6. Very uncomfortable & \\
7. Very hot & & & \\
\hline
\end{tabular}

Table 4: Mean indoor and outdoor parameters

\begin{tabular}{|c|c|c|c|c|c|c|c|c|c|c|c|c|c|c|}
\hline \multirow{3}{*}{ School } & \multicolumn{6}{|c|}{ Temperature $\left({ }^{\circ} \mathrm{C}\right)$} & \multicolumn{4}{|c|}{ Relative humidity (\%) } & \multirow{2}{*}{\multicolumn{2}{|c|}{ Air velocity (m/s) }} & \multirow{2}{*}{\multicolumn{2}{|c|}{$\mathrm{CO}_{2}(\mathrm{ppm})$}} \\
\hline & \multicolumn{2}{|c|}{ Indoor globe } & \multicolumn{2}{|c|}{ Indoor } & \multicolumn{2}{|c|}{ Outdoor } & \multicolumn{2}{|c|}{ Indoor } & \multicolumn{2}{|c|}{ Outdoor } & & & & \\
\hline & Mean & SD & Mean & SD & Mean & SD & Mean & SD & Mean & SD & Mean & SD & Mean & SD \\
\hline $\mathrm{S} 1$ & 28 & 0.6 & 28.3 & 0.7 & 27.7 & 0.7 & 60.8 & 2.8 & 63.3 & 2.8 & 0.06 & 0.05 & 391 & 36.7 \\
\hline $\mathrm{S} 2$ & 30.6 & 0.4 & 30.6 & 0.5 & 33.9 & 0.7 & 48.9 & 3.3 & 41.7 & 3.6 & 0.12 & 0.02 & 450 & 18.9 \\
\hline $\mathrm{S} 3$ & 29.9 & 1.3 & 30.1 & 1.5 & 29.8 & 1.3 & 58.1 & 8.9 & 59.3 & 3.6 & 0.09 & 0.07 & 522 & 162.7 \\
\hline $\mathrm{S} 4$ & 23.5 & 0.2 & 23.5 & 0.2 & 25.5 & 0.7 & 56.8 & 1 & 53.0 & 2.8 & 0.09 & 0.03 & 410 & 25.5 \\
\hline S5 & 27.6 & 0.8 & 27.5 & 0.7 & 27.6 & 0.9 & 50.3 & 1.6 & 51.9 & 2.1 & 0.11 & 0.05 & 483 & 60.3 \\
\hline S6 & 26.4 & 0.5 & 26.4 & 0.5 & 25.4 & 0.6 & 49.2 & 2.8 & 53.9 & 3.1 & 0.10 & 0.04 & 415 & 28.2 \\
\hline S7 & 25.5 & 0.6 & 25.6 & 0.9 & 27.2 & 2.4 & 36.3 & 2.0 & 35.0 & 6.3 & 0.13 & 0.04 & 485 & 58.8 \\
\hline S8 & 24.4 & 1 & 25 & 1 & 25 & 2.6 & 69.1 & 6 & 72.1 & 10.6 & 0.12 & 0.07 & 370 & 17.7 \\
\hline Mean & 27.4 & 2.6 & 27.6 & 2.6 & 28.3 & 3.2 & 53.1 & 10.5 & 52.8 & 12.2 & 0.1 & 0.1 & 454 & 98 \\
\hline
\end{tabular}

S1: Kewalpur Harihar Bhajkumari School (Dhading) S2: Bhuwaneshwori Secondary School (Dhading) S3: Mahankaleshwori Secondary School (Dhading) S4: Jyoti Secondary School (Dhading) S5: Gramsewa Secondary School (Kathmandu) S6: Pragya Commerce College (Kathmandu) S7: Greenland Int'1 Secondary School (Kathmandu) S8: Belkot Bhanjyang Secondary school (Nuwakot)

\subsection{Thermal comfort survey}

Students voted for the perception of thermal sensation, thermal preference, thermal acceptance and overall comfort. The purpose of survey was explained to students and guided to fill up questionnaire. They responded their responses before, middle and end of the class. The sensation scales used in the study are shown in Table 3. For easily understand and better response from students, language [5]. At a height of around $1 \mathrm{~m}$ above the floor the thermal sensation scales were translated into Nepalese level. The instruments were placed at the center of classroom for data.

\section{Results and Discussion}

\subsection{Indoor and outdoor temperatures}

The detailed descriptions of mean indoor and outdoor environmental parameters of each naturally ventilated school buildings are shown in Table 4. In naturally ventilated school buildings, classroom environment is highly influenced by the outdoor environment. In this study, the mean indoor temperature ranged $23-32.6^{\circ} \mathrm{C}$ and mean outdoor temperature $22.3-34.9^{\circ} \mathrm{C}$. The mean indoor temperature was $30.6^{\circ} \mathrm{C}$ which is highest in school S2 and lowest $\left(23.5^{\circ} \mathrm{C}\right)$ in school S4. Due to naturally ventilated buildings, the indoor and outdoor relative humidity was also found to be similar (53\%). The mean air movement was low. No fans and mechanical air conditioning system was observed during field study to maintain the thermal environment of classrooms.

\subsection{Thermal sensation and preference}

The thermal perception of the students was collected using the modified 7-point ASHRAE scale [2]. Figure 2 shows the distribution of students' response in thermal sensation indicating 95\% confidence interval error bars in three districts. In Fanger's thermal comfort model [25], the central three categories of the 7-point TSV are said to be satisfied in their indoor thermal environment. In our study, about $76 \%, 77 \%$ and $77 \%$ responses of the students were found in comfort zone (slightly cold, neutral and slightly 
warm) in the classrooms of Dhading, Kathmandu and Nuwakot districts. The responses on 1. Very cold, 2. Cold, 6. Hot and 7. Very hot can be expressed in thermal dissatisfaction: $24 \%$ (Dhading), 22\% (Kathmandu) and $24 \%$ (Nuwakot). According to the ASHRAE standard [2], classroom need to satisfy $80 \%$ acceptability level. In this study, we found that the classrooms are unable to meet this criterion. As highlighted in Figure 2, 33\% (Dhading) and $38 \%$ (Kathmandu) have more response on 7. Neutral. Nuwakot (29\%) has less responses on neutral. It might be the reason that students were settled in the temporary shelter made by zinc after massive earthquake 2015 . However, the mean thermal sensation of all areas was found to be neutral.

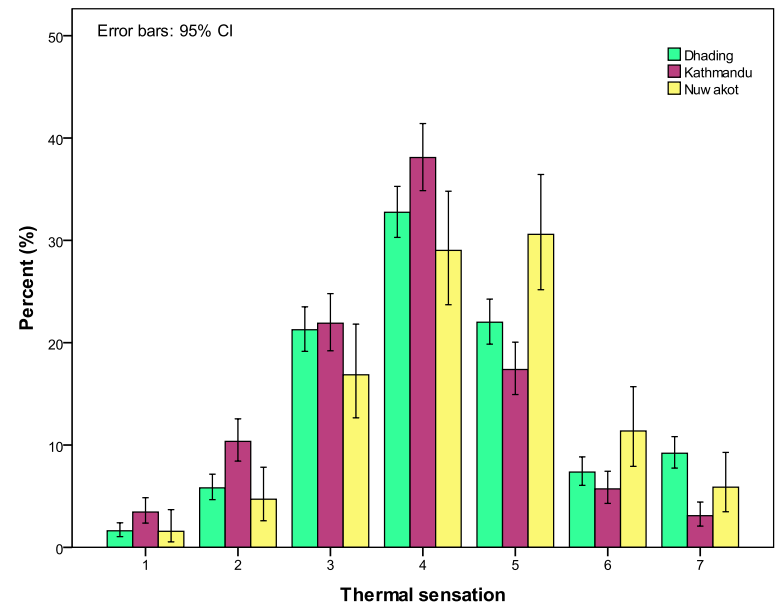

Figure 2: Distribution of thermal sensation

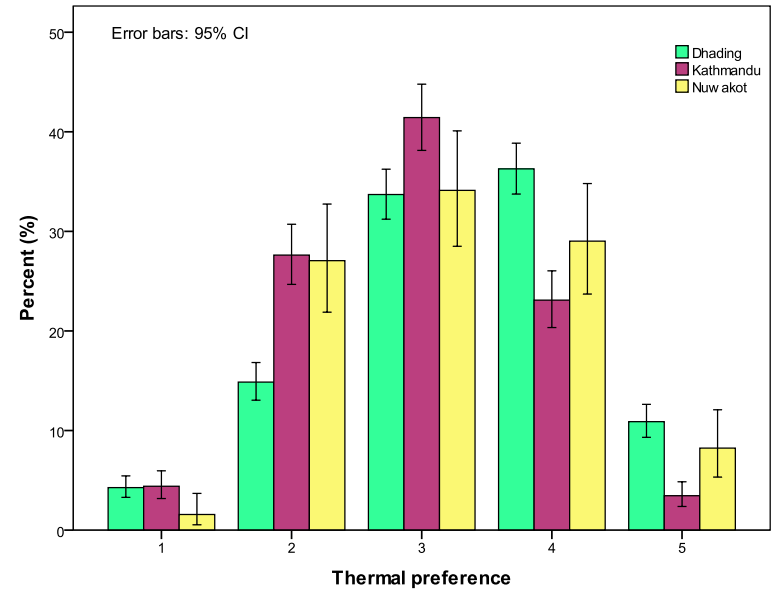

Figure 3: Distribution of thermal preference

Thermal preference (TP) of the students was collected using 5-point thermal preference scale. Figure 3 shows the distribution of students' thermal preference for three districts. Students who responded on "No change": Dhading (34\%), Kathmandu (41\%) and Nuwakot (34\%) were able to accept the indoor environment. It means that they do not want to change their current indoor thermal environment. However, the mean thermal preference for all areas was found to be slightly cooler.

\subsection{Thermal acceptance}

A direct binary question ( 0 . Acceptable, 1 . Unacceptable) were asked to students to obtain responses on thermal acceptance. The distribution of thermal acceptance is shown in Figure 4 . More than $85 \%$ of the responses were acceptable for their immediate classroom environment: Dhading (85\%), Kathmandu (94\%) and Nuwakot (92\%). This result shows the satisfaction of students with their current environments. The restriction of binary response on the question to response might be the reason to have the higher percentage of thermal acceptance.

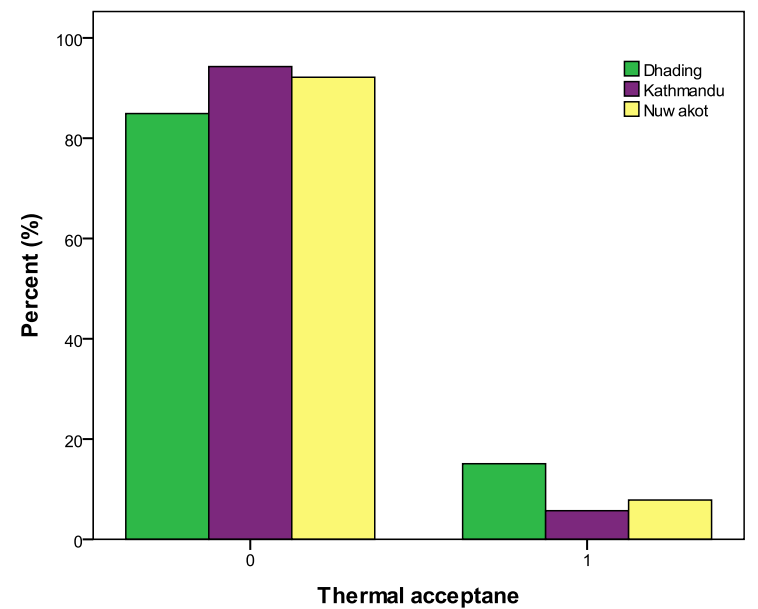

Figure 4: Distribution of thermal acceptance

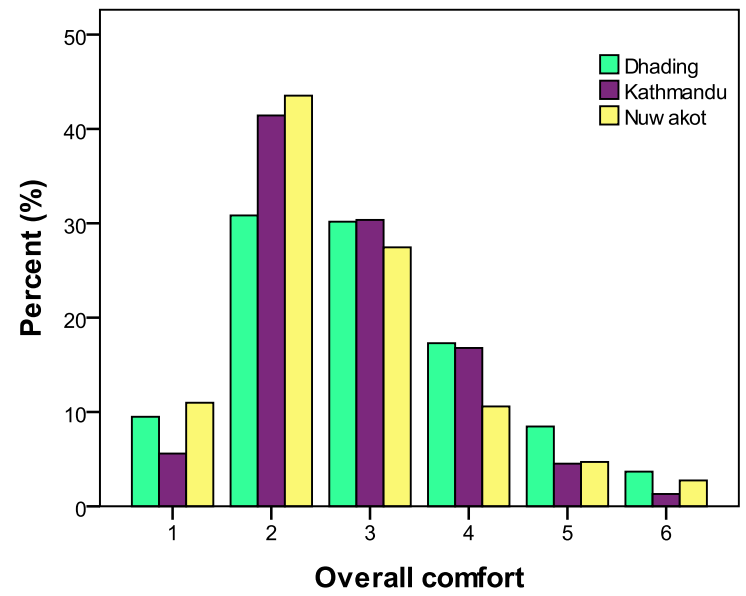

Figure 5: Distribution of the overall comfort

\subsection{Overall comfort}

We obtained responses on current classroom thermal environment using a 6-point scale. The distribution of responses on overall thermal comfort level of students is presented in Figure 5. Most of the responses in all three districts was found to be quite more for moderately comfortable: Dhading (31\%), Kathmandu (41\%) and 
Field Study on Adaptive Thermal Comfort in Naturally Ventilated Secondary School Buildings in Nepal

Nuwakot (44\%). Less percentage of responses was obtained for "very comfortable" and "very uncomfortable".

\subsection{Estimation of comfort temperature}

\subsubsection{Comfort temperature by polynomial regression analysis}

The relationship between the thermal sensation and indoor globe temperature helps to determine the range of comfort temperature. The quadratic regression relationship between the thermal sensation and indoor globe temperature is shown in Figure 6. We classified the responses of students into two binary groups. Very cold, cold, hot and very hot responses are grouped as "uncomfortable". The rest (slightly cold, neutral and slightly warm) are grouped as "comfortable". The ASHRAE -55 [2] suggested the central zone (slightly cold, neutral and slightly hot) as comfortable if $80 \%$ of responses fall within this zone. The combined quadratic regression equation between the proportion of comfortable and indoor globe temperature for three districts are presented below:

$$
\begin{gathered}
P_{\text {comfortable }}=-0.009 T_{g}^{2}+0.521 T_{g}-6.436 \\
\left(\begin{array}{c}
\mathrm{N}=2454, \mathrm{R}_{2}=0.02, \mathrm{~S} . \mathrm{E}_{\cdot 1}=0.001, \\
\mathrm{~S} . \mathrm{E}_{\cdot 2}=0.077, \mathrm{p}<0.001
\end{array}\right)
\end{gathered}
$$

Where $\mathrm{N}$ : Number of responses, $\mathrm{R}_{2}$ : Coefficient of determination, S.E.1 and S.E.2: Standard errors of the regression coefficient of $T^{2}{ }_{g}$ and $T_{g}$ respectively, $\mathrm{p}$ : Significance level of regression coefficient.

The optimum comfort temperature found at the maximum value of $\mathrm{P}_{\text {comfortable }}$ is equal to $28.9^{\circ} \mathrm{C}$. The quadratic regression graph (Figure 6) yields a comfort temperature range of $26-29.5^{\circ} \mathrm{C}$ at $80 \%$ acceptability for all the visited schools of three districts. Dissatisfaction is sharply increased below or above this range of comfort temperature.

We also estimated the comfort temperature $\left(\mathrm{T}_{\mathrm{c}}\right)$ using linear regression (Figure 7). The linear regression equations of thermal sensation and indoor globe temperature for all districts are shown in Table 5. From combined linear regression we found a regression coefficient (sensitivity) of 0.17 thermal sensation per ${ }^{\circ} \mathrm{C}$. It shows a unit change in TSV scale for $6^{\circ} \mathrm{C}$ change in indoor globe temperature. The estimated mean comfort temperature is $27.1^{\circ} \mathrm{C}$.

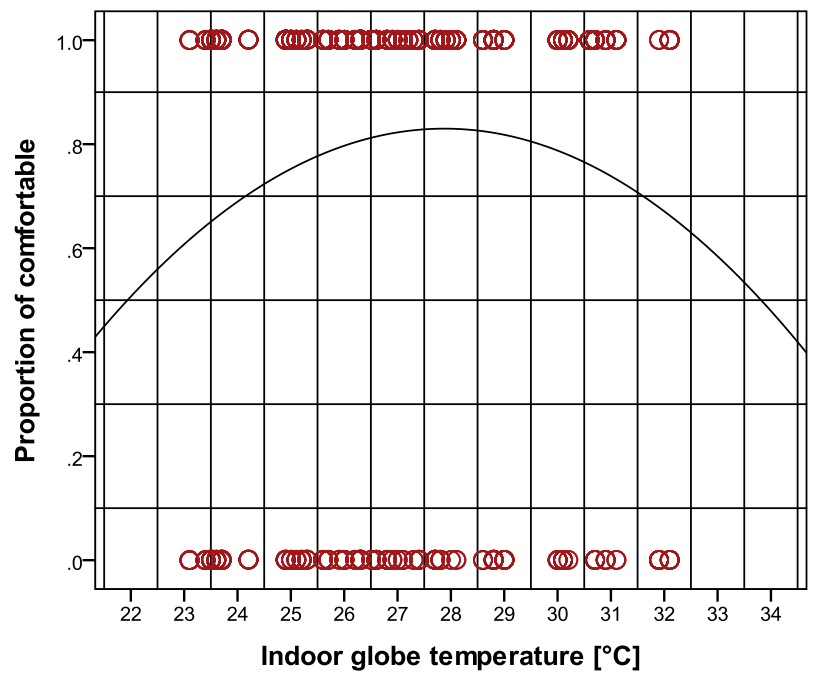

Figure 6: Relationship between proportion of comfortable and indoor globe temperature

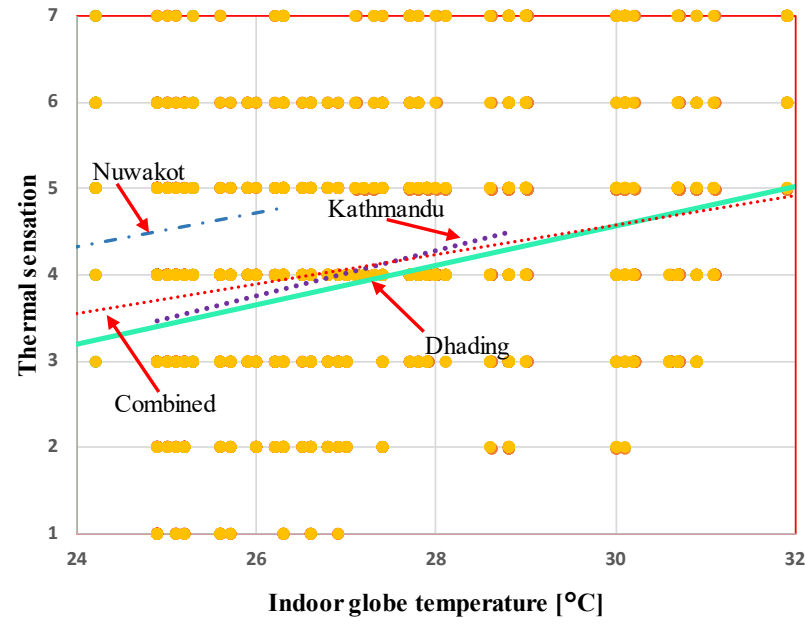

Figure 7: Relationship between the thermal sensation and indoor globe temperature

\subsubsection{Comfort temperature by Griffiths method}

Due to the adaptive behavior of students inside the classroom over a period of time, the regression method

Table 5: Linear regression equation for thermal sensation and thermal preference

\begin{tabular}{lllllllll}
\hline Study areas & Responses (N) & Equations & $\mathbf{R}^{\mathbf{2}}$ & Equations & $\mathbf{R}^{\mathbf{2}}$ & $\boldsymbol{T}_{\boldsymbol{c}}\left[{ }^{\circ} \mathbf{C}\right]$ & $\boldsymbol{T}_{\boldsymbol{p}}\left[{ }^{\circ} \mathbf{C}\right]$ & $\boldsymbol{\Delta t}\left[{ }^{\circ} \mathbf{C}\right]$ \\
\hline Dhading & 1359 & $T S V=0.23 T_{g^{-}} 2.3$ & 0.20 & $T P=0.19 T_{g^{-}} 2.1$ & 0.26 & 27.4 & 26.8 & 0.6 \\
Kathmandu & 840 & $T S V=0.26 T_{g^{-}}-1.1$ & 0.05 & $T P=0.18 T_{g^{-}}-1.7$ & 0.05 & 27.3 & 26.1 & 1.2 \\
Nuwakot & 255 & $T S V=0.20 T_{g^{-}} 0.50$ & 0.03 & $T P=0.27 T_{g^{-}}-3.5$ & 0.08 & 22.5 & 24.1 & -1.6 \\
All & 2454 & $T S V=0.17 T_{g^{-}} 0.6$ & 0.11 & $T P=0.16 T_{g^{-}} 1.2$ & 0.18 & 27.1 & 26.2 & 0.9
\end{tabular}


estimates low value of regression coefficient during regression analysis and hence, gives extraneous comfort temperature value. Therefore, we estimate the comfort temperature using the Griffiths method [5, 26-28]. The following Griffiths equation is used to calculate the comfort temperature.

$$
\mathrm{T}_{\mathrm{c}}=\mathrm{T}_{\mathrm{g}}+\frac{4-T S V}{\mathrm{a}}
$$

Where $T_{c}$ : Comfort temperature $\left({ }^{\circ} \mathrm{C}\right), T_{g}$ : Indoor globe temperature $\left({ }^{\circ} \mathrm{C}\right), T S V$ : Thermal sensation vote and a: Griffiths constant. Figure 8 shows the distribution of Griffiths comfort temperature using 0.50 as the Griffiths constant. The comfort temperature of the students for three districts are $28.1^{\circ} \mathrm{C}, 26.7^{\circ} \mathrm{C}$ and $23.6^{\circ} \mathrm{C}$. The mean comfort temperature for all districts is found to be $27.2^{\circ} \mathrm{C}$.

\subsection{Estimation of preferred temperature}

Students preferred the temperature slightly lower or higher for a hot or cold classroom. The neutral thermal sensation vote does not necessarily mean the students are neutral to indoor classroom environment. There is the possibility of wanting cooler or wanting warmer even experiencing neutral thermal sensation. Figure 9 shows the relationship between the thermal preference and

indoor globe temperature. The regression equations and preferred temperature $\left(T_{p}\right)$ are presented in Table 5. The mean preferred temperature is $26.2^{\circ} \mathrm{C}$. The difference $(\Delta \mathrm{t})$ between the comfort temperature and preferred temperature is found to be small.

\subsection{Acceptability limits on ASHRAE adaptive model}

The ASHRAE-55 [2] adaptive model defines the acceptable zone of comfort temperature for naturally ventilated buildings: $80 \%( \pm 3.5 \mathrm{~K})$ and $90 \%( \pm 2.5 \mathrm{~K})$.

The adaptive model is described using the relationship between the comfort temperature and the outdoor air temperature. To analyze the indoor thermal environment of classroom, we plotted our data in the ASHRAE adaptive model. Figure 10 shows the comfort temperature $\left(T_{c}\right)$ versus outdoor air temperature $\left(T_{o}\right)$ plotted using the following ASHRAE-55 adaptive equation.

$$
\mathrm{T}_{\mathrm{c}}=0.31 \mathrm{~T}_{\mathrm{o}}+17.8
$$

The middle base line with upper and lower limits of comfort zone is shown in the Figure. The diagram illustrates that the comfort temperature of students in naturally ventilated classrooms fall beyond the adaptive limits. Originally, ASHRAE model is developed for the office buildings collecting the huge amount of data from the different parts of the world. The design of the buildings and the behavior of the people in residential and office buildings are different than the school buildings. The adaptive behavior of the students in classroom are limited. The results are in agreement with the results of recent studies [22-24] that describes the students accommodated in naturally ventilated classroom have the wide range of comfort temperature.

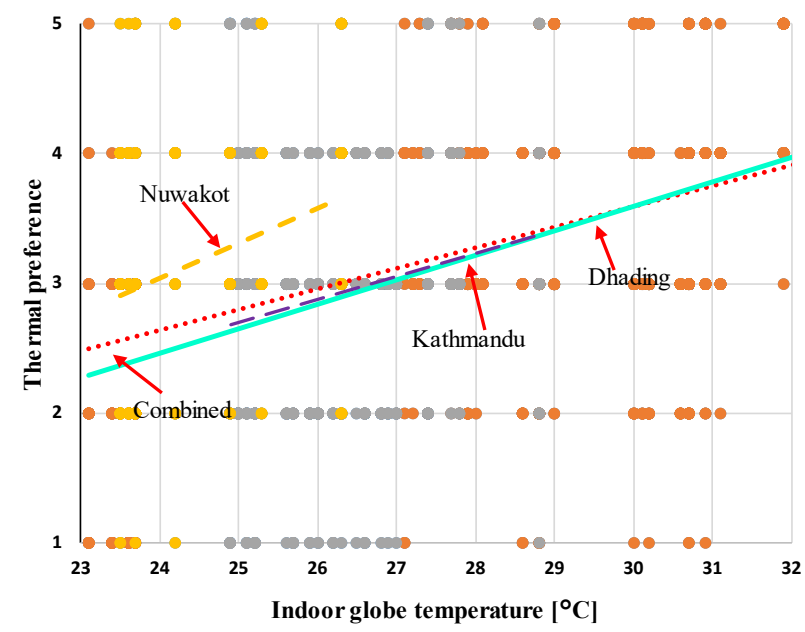

Figure 9: Relationship between the thermal preference and indoor globe temperature

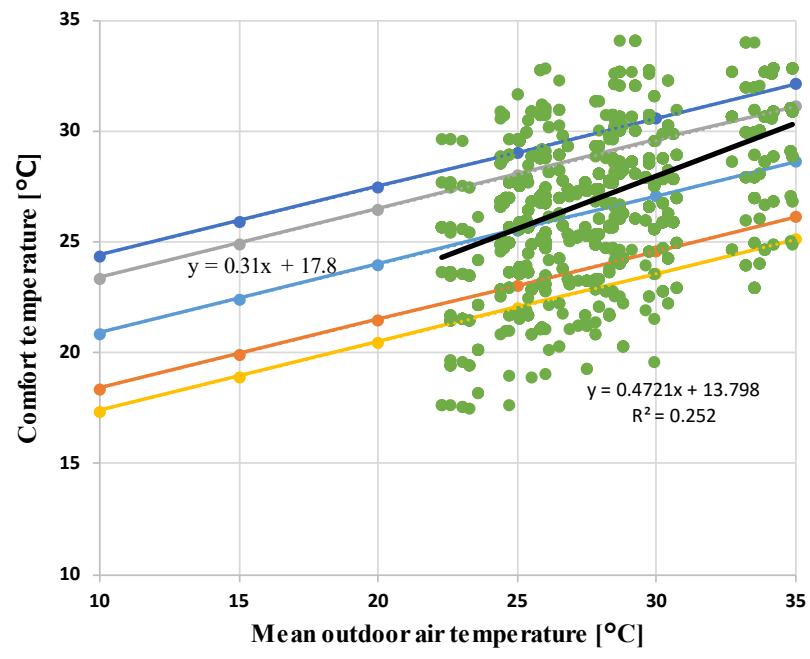

Figure 10: Comparison of comfort temperature with ASHRAE standard

\section{Conclusions}

This paper presents a thermal comfort study conducted for the first time in naturally ventilated school buildings in Nepal for autumn season of 2017. The two simultaneous surveys: measurement survey and questionnaire survey are proposed in the field study. Altogether 2454 responses were obtained form 818 students. The measurements and 
responses are obtained three times in 45 minutes of lecture. The higher neutral temperature and the wider range of acceptable indoor comfort temperature shows that the students might have a higher thermal tolerance level and wider range of adjustment temperature for the naturally ventilated school buildings. Based on the analysis of data collected, we have found the following major results:

1. The indoor environment of the school buildings is found to be slightly warmer. About $76 \%$ responses of the students were found in the comfort zone.

2. The mean thermal sensation and preference was found to be neutral and slightly cooler.

3. The comfort temperature and preferred temperature was found to be around $27^{\circ} \mathrm{C}$ and $26^{\circ} \mathrm{C}$ respectively.

4. The comfort temperature of the students in naturally ventilated school buildings were found beyond the upper and lower limits according to the ASHRAE standard.

\section{Acknowledgments}

We would like to thank all the students and teachers for cooperating in the field study in despite of their regular lesson.

\section{References}

[1] V. De Giuli, O. Da Pos, M. De Carli (2012), Indoor environmental quality and pupil perception in Italian primary schools, Build. Environ, 56: 335-345.

[2] ASHRAE, Thermal environmental conditions for human occupancy, ANSI/ASHRAE standard 55-2017, Atalanta, GA 30329

[3] Martha C. Katafygiotou, Despina K. Serghides, (2014) Thermal comfort of a typical secondary school building in Cyprus, Sustainable Cities and Society, 13: 303-312.

[4] F. Nicol, M. Humphreys (2012), Adaptive thermal comfort: principle and practice.

[5] H.B. Rijal, H. Yoshida, N Umemiya (2010), Regional and seasonal differences in neutral temperatures in Nepalese traditional vernacular houses, Build. Environ., 45: 27432753.

[6] European Committee for Standardization (CEN) EN 15251:2007-2008, Indoor environment input parameter for design of energy performance of buildings, addressing indoor air quality, thermal environment, lighting and acoustics, Comite Europeen de Normalisation, Brussels.

[7] ISO 7730 (2005), Moderate thermal environments Determination of the PMV and PPD indices and specification of the conditions for thermal comfort.
[8] A.G. Kwok (1998), Thermal comfort in tropical classrooms, ASHRAE Tans., 104 (1): 1031-1050.

[9] D. Teli, M.F Jentsch, P.A James (2012), Naturally ventilated classroom: an assessment of existing comfort models for predicting the thermal sensation and preference of primary school children, Energy Build., 53: 166-182.

[10] D. Teli, P.A James, M.F Jentsch (2013), Thermal comfort in naturally ventilated primary school classrooms, Build. Res. Inf., 41: 301-316.

[11] S. Haddad, P. Osmond, S. King (2016), Revisiting thermal comfort models in Iranian classrooms during the warm season, Building Research \& Information http://dx.doi.org/10.1080/09613218.2016.1140950.

[12] R- L. Hwang, T-P. Lin, N-J. Kuo (2006), Field experiments on thermal comfort in campus classrooms in Taiwan, Energy and Buildings, 38: 53-62.

[13] R- L. Hwang, T-P. Lin, C-P. Chen, N-J. Kuo (2009), Investigating the adaptive model of thermal comfort for naturally ventilated school buildings in Taiwan, Int. J. biometeorology, 53: 189-200.

[14] R. de Dear, J. Kim, C. Candido, M. Deuble (2015), Adaptive thermal comfort in Australian school classrooms, Build. Res. Inf., 43(3): 383-398.

[15] Hotter years 'mean lower exam results', https://www.bbc.co.uk/news/business-44288982

[16] G. Zhang, C Zheng, W. Yang, Q. Zhang, D.J. Moschandreas (2007), Thermal comfort investigation of naturally ventilated classrooms in a subtropical region, Indoor Built Environ.16 (2): 148-158.

[17] R. Yao, J. Liu, B. Li (2010), Occupants' adaptive responses and perception of thermal environment in naturally conditioned university classrooms, Appl. Energy, 87: 1015-1022.

[18] H-H Liang, T-P Lin, R-L Hwang (2012), Linking occupants' thermal perception and building thermal performance in naturally ventilated school buildings, Appl. Energy, 94: 355-363.

[19] Z. Wang, H. Ning, X. Zhang, Y. Ji (2016), Human thermal adaptation based on university students in China's server cold area, Sci. Technol. Built Environ., 23: 413-420.

[20] Y. Liu, J. Jiang, D. Wang, J. Liu (2016), The indoor thermal environment of rural school classrooms in Northwestern China, Indoor and Built Environ, 26: 662679.

[21] Z. Fang, S. Zhang, Y. Cheng, A. Fong, M.O Oladokun, Z. Lin, H. Wu (2018), Field study on adaptive comfort in typical air-conditioned classrooms, Buildings and Environment, 133: 73-82

[22] S. Kumar, M.K. Singh, A. Mathur, J. Mathur, S. Mathur, (2018), Evaluation of comfort preferences and insights 
into behavioral adaptation of students in naturally

ventilated classrooms in a tropical country, India, Build.

Environ., 143: 532-547

[23] M. K. Singh, S. Kumar, R. Ooka, H.B. Rijal, G. Gupta, (2018), Status of thermal comfort in naturally ventilated classrooms during the summer season in the composite climate of India, Build. Environ., 128: 287-304

[24] A. Jindal (2018), Thermal comfort study in naturally ventilated school classrooms in composite climate of India, Build. Environ., 142: 34-46

[25] Fanger O. (1970), Thermal Comfort. Copenhagen, Danish technical press.

[26] Griffiths I.D (1990), Thermal comfort in buildings with passive solar features: Field studies. Report to the Commission of the European Communities. EN3S-090 UK: University of Surrey Guildford.

[27] Nicol F., Jamy G.N., Sykes O., Humphreys M., Roaf S., Hancock M. (1994), A survey of thermal comfort in Pakistan toward new indoor temperature standards. Oxford Brookes University, Oxford England.

[28] M.A. Humphreys, H. B. Rijal, J. F. Nicol (2013), Updating the adaptive relation between climate and comfort indoors; new insights and an extended database, Build and Environ., 63: 40-55. 